\title{
Hemşirelerin ağrının farmakolojik olmayan yöntemlerle kontrolüne ilişkin bilgi ve uygulamaları
}

\section{The knowledge and practices of nurses about pain management with non-pharmacological methods}

\author{
Hüsna ÖZVEREN ${ }^{1 a}$, Saide FAYDALI², Selin ÖZDEMIR ${ }^{3}$
}

${ }^{1}$ Kırıkkale Üniversitesi, Sağlık Bilimleri Fakültesi, Kırıkkale, ${ }^{2}$ Necmettin Erbakan Üniversitesi, Sağlık Bilimleri Fakültesi, Konya,

${ }^{3}$ Ankara Üniversitesi İbni Sina Hastanesi, Ankara, TÜRKIYE

\section{Öz}

Amaç: Bu araştırma, hemşirelerin ağrının farmakolojik olmayan yöntemlerle kontrolüne ilişkin bilgi ve uygulamalarını saptamak amacıyla tanımlayıcı olarak yapılmıştır.

Gereç ve Yöntemler: Araştırmanın örneklemini Ankara Üniversitesi İbni-Sina Hastanesi'nin iç hastalıkları ve cerrahi kliniklerinde çalışan toplam 162 hemşire oluşturmuştur. Veriler araştırmacı tarafından geliştirilen soru kağıdı ile toplanmıştır.

Bulgular: Hemşirelerin ağrıyı gidermede kullanılan farmakolojik olmayan yöntemlere ilişkin bilgi puan ortalaması 92 puan üzerinden 38.62 olarak bulunmuştur. Hemşirelerin \%69.9'unun bakım verdikleri bireylerin ağrısını gidermede farmakolojik olmayan yöntemleri uygulamadıkları belirlenmiştir.

Sonuçlar: Çalışma sonucunda hemşirelerin ağrının kontrolünde kullanılan farmakolojik olmayan yöntemleri düşük oranda uyguladıkları ve bu yöntemlere ilişkin bilgilerinin az olduğu belirlenmiştir. Bu sonuçlar doğrultusunda temel hemşirelik eğitiminde ağrının kontrolünde uygulanabilecek farmakolojik olmayan yöntemlerin öğretimine daha fazla yer verilmesi ve uygun tekrarlarının yapılması önerilmektedir.

Anahtar kelimeler: Hemşirelik uygulamaları, farmakolojik olmayan yöntemler, Ağrı yönetimi

\footnotetext{
Corresponding Authora: Hüsna Özveren. Kırıkkale Üniversitesi, Sağlık Bilimleri Fakültesi,

Kırıkkale, TURKEY

Phone: 00903183573738

e-mail: ozverenhusna@gmail.com

Received 26.01.2016, accepted 23.03.2016

5-9 Ekim 2011 tarihleri arasında yapılmış olan 13. Ulusal İç Hastalıkları Kongresinde Poster Bildiri olarak sunulmuştur.
} 


\section{ABSTRACT}

Aim: This study has been made in order to determine the knowledge and practices of the nurses about pain management with non-pharmacological methods.

Material and Methods: 162 nurses who work in the medical and surgical clinics of a university Hospital have constituted the sample of the study. The data were collected through a questionnaire prepared by the researchers based on the literature.

Results: The point average of knowledge of nurses about the non-pharmacological methods which are used to pain management is 38.62 out of 92 points. $\% 69.9$ of the nurses has explained that they do not use the non-pharmacological methods to stop the pain of the patient.

Conclusion: The results of the study assert that the nurses apply non-pharmacological methods in low-levels which are used for pain management and their knowledge about these methods is insufficient. In accordance with these results it is recommended to give more space for teaching the non-pharmacological methods that can be applied for pain management and to make appropriate repetitions.

Keywords: Nursing practices, non-pharmacological methods, pain management

\section{Giriş}

Ağrı, insanoğlunun yaşadığı en karmaşık sağlık sorunlarından biri olup ağrı bireyin günlük yaşam aktivitelerini engelleyen ve yaşam kalitesini etkileyen bir durumdur [1-3]. Ağrının kontrolünde yaygın olarak farmakolojik yöntemler kullanılmaktadır. Farmakolojik yöntem ağrının ilaçla kontrolüdür. Günümüzde farmakolojik tedavi, çabuk etki gösterdiği ve kolay uygulanabildiği için ağrı kontrolünde en çok tercih edilen yöntemlerinden biridir [3,4]. Ağrının kontrol altına alınmasında diğer bir tedavi yöntemi ise farmakolojik olmayan yöntemlerdir. Farmakolojik olmayan yöntemler, ağrının ilaç dışı yöntemlerle kontrol edilmesidir. Analjeziklerin kullanılamadığı ya da etkileri yetersiz kaldığında, ilaçların etkisini artırmak için farmakolojik olmayan yöntemlerden yararlanılmaktadır. Farmakolojik olmayan yöntemler; bireysel kontrol hissini artırarak, bireyde güçsüzlük hissini azaltarak, aktivite düzeyini artırarak, stres ve anksiyeteyi azaltarak, analjezik ilaçların dozunu azaltarak ve ağrı düzeyini azaltarak etki gösterirler. Farmakolojik olmayan yöntemler, ağrının bilişsel, davranışsal ve sosyokültürel boyutunu tedavi etmeyi amaçlamaktadır [2,5-8].

Farmakolojik olmayan yöntemler, periferal teknikler (masaj, sıcak-soğuk uygulama, terapotik dokunma gibi), kognitif (bilişsel) - davranışsal teknikler (meditasyon, yoga, dikkati başka yöne çekme, hayal kurma gibi) ve bu iki yöntemin dışında kalan diğer teknikler (akupunktur, plasebo uygulaması, cerrahi tedavi gibi) olarak kullanılmaktadır. [2,5,8].Yapılan çalışmalar gerek periferal tekniklerin gerekse bilişsel-davranışsal tekniklerin ağrının giderilmesinde ya da şiddetinin azaltılmasında etkili olduğunu ortaya koymaktadır [9-12]. Örneğin; Kubsch ve ark. tarafından yapılan bir çalışmada [11] acil servise gelen hastalarda deri uyarımının ağrının azaltılması ve hastaların kan basıncı ve kalp hızı üzerine etkileri araştııımıştır. 50 hasta üzerinde yapılan çalışma sonucunda, deri uyarımı uygulanan hastaların ağrııının önemli derecede azaldığı kalp hızında ve kan basıncında düşme olduğu saptanmıştır. Yine Good ve ark. [10] 468 hasta üzerinde yaptığı çalışmalarında, gevşemenin, müziğin ve ikisinin birlikte kullanımının postoperatif ağrıyı azaltmadaki etkisi incelenmiştir. Bu tekniklerin üçünün birlikte kullanımının hastaların ağrı algılamasını azalttığı saptanmıştır. İyi bir ağrı kontrolü ağıı değerlendirmesi ile başlar. Başarılı bir ağrı kontrolü için, hastanın ağrısının doğru değerlendirilmesi ve ağrı kontrolünde etkili olabilecek yöntemlerin belirlenmesi açısından son derece önemlidir. Ağrı tedavisi multidisipliner ekip yaklaşımı gerektirir. Bu ekibin vazgeçilmez üyelerinden biri de hemşiredir [13-14]. Hemşirelerin diğer sağlık çalışanlarına kıyasla hastalarla daha uzun süre birlikte olmaları ve hastanın ağrısını giderme ve azaltmada primer rolleri nedeniyle ağrı yönetimi konusunda yeterli bilgiye sahibi olmaları çokönemlidir [15-16]. Hemşire bireyin ağrısını en aza indirmek için ağrıyla ilgili bilgisini kullanarak ağrının kontrolü için gerekli uygulamaları yapmalıdır. Aynı zamanda hemşirenin ağrı konusunda bilgili, duyarlı olması, iletişim kurma becerisinin olması ve empati yapabilmesi ağrıyı gidermede etkili bir hemşirelik bakımının planlanmasında önemlidir. Bu yüzden hemşirelerin ağrısı olan hastanın bakımında önemli rolleri vardır.

Hemşirelere bu bilgi ve becerilerin kazandırılması eğitimleri sırasında temel hemşirelik meslek dersleri içinde ve bunun yanı sıra fizyoloji, farmakoloji gibi diğer derslerin içinde de ağıı ve ağrı tedavisi ile ilgili dersler verilerek kazandırımaktadır. Aynı zamanda hemşirelere çalışma hayatında hizmet içi eğitim programlarında da ağrı yönetimi ile ilgili bilgiler de almaktadırlar. Ağrının kontrolünde kullanılan bazı farmakolojik olmayan yöntemler (terapötik dokunma, TENS, akapunktur, biyolojik geri bildirim gibi) için hemşirenin özel eğitim almış olması gerekebilir [2-5]. Fakat hemşireler ağrının kontrolünde kullanılan masaj, sıcak uygulama, soğuk uygulama, deriye 
mentol uygulama, gevşeme yöntemleri, dikkati başka yöne çekme, müzik, hayal kurma gibi yöntemleri ise özel bir eğitim almaksızın hemşirelik eğitimleri sırasında aldıkları bilgilerle uygulayabilirler. Ağrı tedavisinde kliniklerde farmakolojik olmayan yöntemlerin uygulanması hemşirelerin bağımsız rollerini rahatlıkla ortaya koyabilecekleri bir alandır $[8,17]$.

Ağrı çalıştığı bölüm her ne olursa olsun hemşirelerin en sık karşılaştığı problemlerden biridir. Bu sıklık yüzünden hemşireler ağrı yönetiminden sorumludurlar. Bu sorumluluk hemşirelerin kliniklerde hastanın ağrısının farkında olmaları, ağrının giderilmesinde ve değerlendirilmesinde rol almaları, hastalara girişimde bulunmaları ve bu bilgileri çalıştıkları kurumlarda kullanmaları beklenmektedir. Bu nedenle bu çalışma, hemşirelerin ağrıyı gidermede özel eğitim almaksızın uygulayabilecekleribazı farmakolojikolmayanyöntemlereilişkin bilgi düzeyleri ve bu bilgileri kliniklerde uygulama durumları konusunda aydınlatıcı olacaktır. Bu araştırma, hemşirelerin ağrının farmakolojik olmayan yöntemlerle kontrolüne ilişkin bilgi ve uygulamalarını saptamak amacıyla yapılmıştır.

\section{Gereç ve Yöntemler}

Bu araştırma, hemşirelerin ağrının farmakolojik olmayan yöntemlerle kontrolüne ilişkin bilgi ve uygulamalarını saptamak amacıyla yapılmış, tanımlayıcı bir çalışmadır. Araştırmanın evrenini, bir üniversite hastanesinin iç hastalıkları ve cerrahi kliniklerinde çalışan toplam 249 hemşire oluşturmuştur. Hemşireden 192'si çalışmaya katılmayı kabul etmiştir. Bu hemşirelerden bir kısmı çalışmaya katılmaktan vazgeçtiği, bir kısmı ise soru kağıdını eksik yanıtladığı için 30 hemşire çalışmaya dahil edilmemiş ve çalışma 162 hemşire ile tamamlanmıştır.

Araştırmanın verileri, araştırmacılar tarafından literatüre dayalı olarak hazırlanan $[2,5,6,8]$ anket formu aracılığı ile toplanmıştır. Anket formu üç bölümden oluşmakta olup, birinci bölümde hemşirelerin tanıtıcı özelliklerini içeren sorular, ikinci bölümde hemşirelerin ağrıya ilişkin uygulamalarını içeren sorular, üçüncü bölümde ise hemşirelerin farmakolojik olmayan yöntemlere ilişkin bilgilerini içeren sorular yer almaktadır. Araştırmanın ön uygulaması 10 hemşire ile gerçekleştirilmiştir. Ön uygulama sonucunda soru kağıdında gerekli düzenlemeler yapılmıştır.

Araştırma Helsinki illkeleri Deklerasyonuna uygun olarak hazırlanmış, uygulamaya başlanmadan önce araştırmanın yapılacağı kurumdan yazılı izin, Ankara Üniversitesi Tıp Fakültesi Klinik Araştırmalar Etik Kurulundan etik kurul kararı alınmıştır. Araştırmaya katılan hemşirelere araştırmaya katılıp katılmama konusundaki kararın tamamen kendilerine ait olduğu, anket formuna isim yazmamaları, bu çalışmadan toplanılacak verilerin sadece araştırma kapsamında kulanılacağı, gizliliğin kesinlikle sağlanacağı belirtilmiş, araştırma konusunda açıklama yapıldıktan sonra sözel ve yazılı onamları alınmıştır. Verilerin değerlendirilmesinde sayı, yüzde, ortalama, iki ortalama arasında farkın anlamlılık testi ve varyans analizi kullanılmıştır.
Araştırmada hemşirelerin yalnızca okulda aldıkları eğitimle ve bağımsız olarak yapabilecekleri yöntemlere (masaj, sıcak uygulama, soğuk uygulama, deriye mentol uygulama, gevşeme yöntemleri, dikkati başka yöne çekme, müzik ve hayal kurma) ilişkin bilgileri araştırılmıştır. Bunların dışında kalan diğer farmakolojik olmayan yöntemler özel eğitim ve uygulama becerisi gerektirdiğinden hemşirelerin bunlara ilişkin bilgileri dikkate alınmamıştır.

\section{Bulgular}

Tablo 1'de hemşirelerin tanıtıcı özelliklerine ilişkin bulgular yer almaktadır. Hemşirelerin yarıdan fazlası (\%52,8) 21-23 yaş grubundadır ve \%40,9'unun önlisans, \%34,2'sinin lisans mezunu olduğu saptanmıştır. Hemşirelerin \%54,9'unun iç hastalıkları kliniklerinde, \%45,1'inin ise cerrahi hastalıkları kliniklerinde çalıştığı ve \%88,6'sının 4 yıl ve üzerinde hemşirelik deneyimine sahip olduğu belirlenmiştir. Hemşirelerin \%60,6'sı farmakolojik olmayan yöntemlere ilişkin bilgi aldıklarını ve \%27,5'i bu bilgilerini temel eğitimleri sırasında aldıklarını ifade etmiştir. Hemşirelerin hastaların ağrılarını gidermede farmakolojik olmayan yöntemlere ilişkin bilgi almak istedikleri ve en fazla bilgi almak istedikleri yöntemin \%50,8'lik oranla gevşeme yöntemleri olduğu belirlenmiştir.

Tablo 2'de hemşirelerin ağrının farmakolojik olmayan yöntemlerle tedavisine ilişkin görüş ve uygulamalarının dağılımı yer almaktadır. Araştırmaya katılan hemşirelerin \%73,6'sı farmakolojik olmayan yöntemlerin kliniklerde bazen uygulanması gerektiğini belirtmiştir. Bakım verdikleri bireylerin ağrısını gidermede hemşirelerin \%69,9'u farmakolojik olmayan yöntemleri uygulamadıklarını belirtmişlerdir. Hemşirelerde farmakolojik olmayan yöntemleri uygulamama nedeni olarak ise \%45,1'lik bir oranda hemşirenin iş yükünü artırdığını, ve hemşire sayısının yetersiz olduğunu belirtmiştir. Hemşireler tarafından hastaların ağrısını gidermede uyguladıkları yöntemlerin \%98.4'ünün doktor istemine göre analjezik uygulama, \%44,0'ünün plasebo uygulama, \%35,2'sinin dikkati başka yöne çekme \%31,0'inin soğuk uygulama, \%4,7'sinin deriye mentol uygulama ve düşük oranlarda müzik dinleme $(\% 3,1)$ ve hayal kurma $(\% 2,1)$ olduğu görülmektedir.

Tablo 3'de hemşirelerin tanıtıcı özelliklerine göre farmakolojik olmayan yöntemlere ilişkin bilgi puan ortalamaları yer almaktadır. Hemşirelerin ağrının kontrolünde kullanılan farmakolojik olmayan yöntemlere ilişkin bilgi puanları toplam 92,00 puan üzerinden değerlendirilmiştir. Hemşirelerin ağrıyı gidermede kullanılan farmakolojik olmayan yöntemlere ilişkin aldıkları bilgi puan ortalaması 38,62'dir. Araştırma kapsamına giren hemşirelerin hiçbirinin tam puan almadığı, alınan en düşük puanın 14,00 en yüksek puanın ise 68,00 olduğu saptanmıştır. 


\begin{tabular}{|c|c|c|}
\hline Yaş & Sayı & $\%$ \\
\hline 21-33 Yaş & 102 & 52,8 \\
\hline 34-53 Yaş & 91 & 47,2 \\
\hline \multicolumn{3}{|l|}{ Medeni Durum } \\
\hline Evli & 123 & 63,7 \\
\hline Bekar & 70 & 36,3 \\
\hline \multicolumn{3}{|l|}{ Eğitim Durumu } \\
\hline Sağlık Meslek Lisesi & 45 & 23,3 \\
\hline Önlisans & 79 & 40,9 \\
\hline Lisans & 66 & 34,2 \\
\hline Lisansüstü & 3 & 1,6 \\
\hline \multicolumn{3}{|l|}{ Çalışmakta Olduğu Klinik } \\
\hline İç Hastalıkları Kliniği & 106 & 54,9 \\
\hline Cerrahi Hastalıkları Kliniği & 87 & 45,1 \\
\hline \multicolumn{3}{|l|}{ Çalışma Yılı } \\
\hline $1-3 Y_{I I}$ & 22 & 11,4 \\
\hline 4 Yıl Ve Üzeri & 171 & 88,6 \\
\hline \multicolumn{3}{|l|}{$\begin{array}{l}\text { Hemşirelerin Farmakolojik Olmayan } \\
\text { Yöntemlere İlişkin Bilgi Alma Durumu }\end{array}$} \\
\hline Bilgi Alan & 117 & 60,6 \\
\hline Bilgi Almayan & 76 & 39,4 \\
\hline \multicolumn{3}{|l|}{ Bilgi Alanların Yararlandıkları Kaynaklar } \\
\hline Temel Hemşirelik Eğitiminde (Lise,Önlisans,Lisans,Lisansüstü) & 53 & 27,5 \\
\hline Hizmetiçi Eğitimde & 37 & 19,2 \\
\hline Bilimsel Faaliyetlerde (Kongre, Konferans Vb.) & 21 & 20,9 \\
\hline İnternet, Kitap, Dergi Vb. & 49 & 25,4 \\
\hline \multicolumn{3}{|l|}{ Daha Fazla Bilgi Almak İstedikleri Konular } \\
\hline Analjezik Uygulama & 84 & 43,5 \\
\hline Masaj & 72 & 37,3 \\
\hline Sıcak Uygulama & 45 & 23,3 \\
\hline Soğuk Uygulama & 45 & 23,3 \\
\hline Deriye Mentol Uygulama & 48 & 24,9 \\
\hline Dikkati Başka Yöne Çekme & 64 & 33,2 \\
\hline Hayal Kurma & 26 & 13,5 \\
\hline Plasebo & 51 & 26,4 \\
\hline Müzik & 41 & 21,2 \\
\hline Gevşeme Egzersizleri & 98 & 50,8 \\
\hline Hiçbiri & 4 & 2,1 \\
\hline
\end{tabular}




\begin{tabular}{|l|c|c|c|}
\hline Tablo 3. Hemşirelerin Bazı Tanıtııı Özelliklerine Göre Farmakolojik Olmayan Yöntemlere Illişkin Bilgi Puan Ortalamaları \\
\hline Tanıtıcı Özellikler & $\overline{\mathbf{x}}$ & $\mathbf{S S}$ & $\begin{array}{c}\text { İstatistiksel } \\
\text { Değerlendirme }\end{array}$ \\
\hline Genel Bilgi Puanları & 38,62 & $\pm 10,99$ & \\
\hline Yaş & & & \\
\hline 33 yaş altı & 37,58 & $\pm 11,71$ & $\mathrm{t}=1,368$ \\
\hline 33 yaş üstü & 39,95 & $\pm 9,90$ & $\mathrm{P}=0,173$ \\
\hline Mezun Olunan Okul & & & \\
\hline Sağlık Meslek Lisesi & 35,05 & $\pm 1,87$ & $\mathrm{~F}=1.606$ \\
\hline Ön Lisans & 39,79 & $\pm 1,26$ & $\mathrm{P}=0,190$ \\
\hline Lisans & 39,48 & $\pm 1,45$ & \\
\hline Lisansüstü & 38,33 & $\pm 10,33$ & \\
\hline Çalıştığı Klinik & & & \\
\hline Iç Hastalıkları Kliniği & 38,36 & $\pm 10,10$ & $\mathrm{t}=0,310$ \\
\hline Cerrahi hastalıkları Kliniği & 38,89 & $\pm 11,91$ & $\mathrm{P}=0,757$ \\
\hline Çalışma Yılı & & & \\
\hline 1-3 yıl & 43,5 & $\pm 16,6$ & $\mathrm{t}=0,039$ \\
\hline 4yıl ve üzeri & 43,1 & $\pm 12,5$ & $\mathrm{P}=0,969$ \\
\hline $\begin{array}{l}\text { Klinikte Farmakolojik Olmayan } \\
\text { Yöntemleri Uygulama Durumu }\end{array}$ & & & \\
\hline Evet & & & \\
\hline Hayır & 41,02 & $\pm 12,85$ & $\mathrm{t}=1,776$ \\
\hline $\begin{array}{l}\text { Hemşirenin Farmakolojik Olmayan } \\
\text { Yöntemlere ilişkin Bilgi Alma Durumu }\end{array}$ & 37,68 & $\pm 10,01$ & $\mathrm{P}=0,078$ \\
\hline Evet & 40,5 & $\pm 10,93$ & $\mathrm{t}=2,946$ \\
\hline Hayır & 35,33 & $\pm 10,39$ & $\mathrm{P}=0,004$ \\
\hline
\end{tabular}

Araştırmada hemşirelerin tanıtıcı özelliklerine göre farmakolojik olmayan yöntemlere ilişkin bilgi puan ortalamalarına da bakılmış ancak, yapılan istatistiksel değerlendirmelerde tanıtıcı özelliklerine göre (yaş, medeni durum, mezun olunan okul, çalışmakta olduğu klinik, çalışma yılı, klinikte farmakolojik olmayan yöntemleri uygulama durumu) bilgi puan ortalamaları arasında farkın anlamlı olmadığı $(P>0,05)$ saptanmıştır.

Hemşirelerin farmakolojik olmayan yöntemlere ilişkin bilgi alma durumlarına göre bilgi puan ortalamalarına bakıldığında, bilgi alanların puan ortalamasının 40,5, bilgi almayanların puan ortalamasının 35,3 olduğu görülmektedir. Yapılan istatistiksel değerlendirme sonucunda her iki grubun bilgi puan ortalamaları arasındaki fark anlamlı bulunmuştur $(P<0,05)$.

\section{Tartışma}

Ağrı hemşireler tarafından çok sık karşılaşılan durumlardan biridir. Hastanede yatan hastalar ya hastalıkları ya da bazı işlemler nedeniyle ağrı yaşamaktadır. Bu nedenle hemşirenin hastanın ağrısını gidermek ve en aza indirmek için uygun yöntemleri seçmesi ve uygulaması önemlidir. Çalışmamızda hemşirelerin \%69,9'unun bakım verdikleri hastaların ağrısını gidermede farmakolojik olmayan yöntemleri uygulamadıkları ve hemşirelerin \%73,6'sının farmakolojik olmayan yöntemlerin kliniklerde bazen uygulanması gerektiğini belirttikleri görülmektedir (Tablo 2). Hemşirelerin bu yöntemleri uygulamama nedenleri arasında ise en yüksek oranda $(\% 45,0)$ hemşirenin iş yükünü artırdığı ve hemşire sayısı yetersizliğinin geldiği belirtilmektedir. Yapılan bazı çalışmalarda [18-19] hemşirelerin farmakolojik olmayan yöntemleri uygulamama nedenleriarasında;bilgieksikliği,zamanyetersizliğivetutumları olduğunu göstermektedir. He ve ark. [18] yaptıkları çalışmada hemşirelerin farmakolojik olmayan yöntemleri kullanmama nedenlerinin iş yükü, zaman yetersizliği, malzeme eksikliği ve bilgi yetersizliği olduğunu saptamıştır. Benzer şekilde Bicek'in [19] yaptığı çalışmada, hemşirelerin farmakolojik yöntemleri uygulamama nedenlerini hastaların isteksizliği, zaman ve bilgi yetersizliği olduğunu belirtmektedir. Çalışmamızın sonuçları literatür bilgisiyle parelellik göstermektedir.

Hemşireler çalışmamızda klinikte ağrısı olan bireye bakım verirken en çok doktor istemine göre analjezik verdiğini (\%98.4) ifade etmiştir (Tablo 2). Kliniklerde hemşirelerin ağrı probleminin azaltılması ya da ortadan kaldırılması için genellikle hekim istemi ile analjezikleri uyguladıkları bilinmektedir. Yapılan bazı çalışmalarda $[20,21]$ bu durumu desteklemektedir. Örneğin, Ay ve Ecevit'in [20] postoperatif ağrı ve hemşirelik uygulamaları ile ilgili çalışmalarında hemşirelerin ağrının giderilmesine yönelik yaptıkları 
uygulamaların \%77,2'sinin hekim istemine yönelik tedaviye ait olduğu bulunmuştur. Benzer şekilde Özveren'in [21] yaptığı çalışmada da, öğrenci hemşireler tarafından da hastaların ağrısını gidermede \%20,6'sının doktor istemine göre analjezik verme olduğu saptanmıştır.

Çalışmamızda hemşirelerin klinikte hastaların ağrılarını gidermede kullandığı yöntemlere bakıldığında, hemşirelerin ağrı kontrolünde farmakolojik olmayan yöntemleri göz ardı ettikleri görülmektedir (Tablo 2). Yapılan çalışmalarda [20,22-24] hemşirelerin genellikle ağrının kontrolünde kullanılan ilaç tedavisini yeterli buldukları ve farmakolojik olmayan yöntemleri yeterince kullanmadıkları saptanmıştır. Oysaki kullanılan farmakolojik olmayan yöntemlerin ağrıyı azalttığı, yan etkilerinin olmadığı ve hastanın özbakımın güçlendirmesinde önemli rol oynadığı bilinmektedir [4].

Hemşirelerin hastalarının ağrısını gidermede en fazla dikkati başka yöne çekmeyi, sıcak-soğuk uygulamayı ve gevşeme egzersizlerini kullandıkları görülmektedir (Tablo 2). Hemşirelerin seçtikleri bu yöntemlerin bireylerde rahatsızlığa neden olmayan, bakım verdikleri bireylerin kolay kabul ettikleri ve rahatlıkla uygulayabilecekleri yöntemler olduğu görülmektedir. Ayrıca hemşirelerin bu yöntemleri seçmesine bireylerin evde de sıklıkla bu yöntemleri kullanıyor olması bir neden olabilir. Bicek'in [19] yaptığı çalışmada, hemşirelerin hastaların ağrısını gidermede en fazla pozisyon değiş̧ikliği, masaj, sıcak-soğuk uygulama ve gevşeme egzersizlerini kullandıkları belirlenmiştir.

Yukarıdaki yöntemlerin dışında kalan hayal kurma, müzik dinleme ve deriye mentol uygulaması yöntemlerini hemşirelerin daha az kullandıkları görülmüştür (Tablo 2). Hemşirelerin bu yöntemleri daha az kullanmalarında belirtilen yöntemlerle ilgili bilgilerinin yetersiz olması bir neden olabilir.

Ayrıca çalışmamızda hemşirelerin hastaların ağrılarını gidermede yarıya yakınının $(\% 44,0)$ plasebo kullanması dikkati çekmektedir. Oysa plasebo kullanılarak ağrının giderilmesi gecikmekte, hastanın daha fazla acı çekmesine neden olmakta ve bu durum etik açıdan uygun bulunmamaktadır [25].

Hemşirelerin ağrıyı gidermede kullanılan farmakolojik olmayan yöntemlere ilişkin bilgi düzeylerine bakıldığında alınacak en yüksek puan 92,0 iken bilgi düzeylerinin 38,6 puan ortalamasıyla az düzeyde olduğu saptanmıştır. Bu bulgu, hemşirelerin farmakolojik olmayan yöntemlere ilişkin bilgi düzeylerinin istenilen seviyede olmadığını göstermektedir. Temel hemşirelik eğitiminde farmakolojik olmayan yöntemler öğretilmektedir ancak hemşireler bu yöntemleri pratikte çok az gözlemledikleri ya da yaptıkları için bilgilerini unutmuş olabilirler. Farmakolojik olmayan yöntemlerin ağrı kontrolünde kullanılması gerektiği özellikle son yıllarda hem ders kitaplarında hem de çalışmalarda vurgulanmaktadır $[6,7]$ Farmakolojik olmayan yöntemlere ilişkin yapılan çalışmalarda, bu yöntemlere ilişkin hemşirelerin ciddi bilgi eksikliklerinin olduğunu göstermektedir [26-29]. Çalışmamızda da hemşirelerin farmakolojik olmayan yöntemlere ilişkin bilgi eksikliğinin olması (Tablo 3) literatürü desteklemektedir. Bu nedenle farmakolojik olmayan yöntemlerin kullanımının sağlanması için belirlenen en önemli stratejilerden biri eğitimdir. Çalışmamızın sonucu da, ağrı kontrolünde özellikle farmakolojik olmayan yöntemlerle ilgili hemşirelerin sürekli eğitiminin gerekli olduğunu göstermiştir.

Hemşirelerin farmakolojik olmayan yöntemlere ilişkin bilgi alma durumlarına göre bilgi puan ortalamalarına bakıldığında, gruplar arasında istatistiksel olarak anlamlı bir fark bulunmuştur ( $P<0,05)$. Hemşirelerin farmakolojik olmayan yöntemlere ilişkin bilgi düzeyi arttıkça klinikte bakım verdikleri bireylere de uygulamaları artacaktır.

Sonuç olarak, hemşirelerin ağrının kontrolünde kullanılan farmakolojik olmayan yöntemleri düşük oranda uyguladıklarını ve bu yöntemlere ilişkin bilgilerinin az olduğunu ortaya koymuştur. Bu sonuçlar doğrultusunda temel hemşirelik eğitiminde ağrının kontrolünde uygulanabilecek farmakolojik olmayan yöntemlerin öğretimine daha fazla yer verilmesi ve uygun tekrarlarının yapılması; hizmet içi eğitim programlarında farmakolojik olmayan yöntemler konusuna yer verilmesi önerilmektedir.

\section{Maddi Destek ve Çıkar İlişkisi}

Çalışmayı maddi olarak destekleyen kişi/kuruluş yoktur ve yazarların çıkara dayalı bir ilişkisi yoktur.

\section{Teşekkür Yazısı}

Bu çalışmanın anket uygulamasına katkılarından dolayı Ankara Üniversitesi İbni-Sina Hastanesi hemşirelerine teşekkür ederiz.

\section{Kaynaklar}

1. Büyükyılmaz $F$, Aştı $T$. Ameliyat sonrası ağrıda hemşirelik bakımı. Atatürk Üniversitesi Hemşirelik Yüksek Okulu Dergisi 2009; 12: 84-93.

2. Nadler DO, Scott F. Nonpharmacologic management of pain. Journal of the American Osteopathic Association 2004;104: 6-12.

3. Yentür EA. Ağrı ve yaşam kalitesi. II. Sağlıkta yaşam kalitesi kongresi. 2007; 12-3.

4. Nester TM, Hale LS. Effectiveness of pharmacist acquired medication history in promoting patient safety. Am J Health Syst Pharm 2002; 59: 2221-5.

5. Adams DP, Melissa L, Gary J, et al. Non-Pharmacologic pain management Intervention. Clin Podiatr Med Surg 2008; 25: 409-429.

6. Atabek Aştı T, Karadağ A. Hemşirelik Esasları. Hemşirelik Bilim ve Sanatı. İstanbul, Akademi Basın ve Yayıncılık; 2014.

7. Sabuncu N, Akça AF. Klinik Beceriler. Sabuncu N, Akçay AF. ed. Ağrı AğrıyaYönelik Uygulamalar ve Hasta Bakımı. 1. Baskı. Ankara, Nobel Tıp Kitabevi; 2011.

8. Özveren H. Ağrı Kontrolünde Farmakolojik Olmayan Yöntemler Sağlık Bilimleri Fakültesi Hemşirelik Dergisi 2011;18: 83-92. 
9. Anderson KO, Cohen MZ,MendozaTR, etal. Briefcognitive-behavioral audiotape interventions for cancer-related pain: Immediate but not long-term effectiveness. Cancer 2006; 107: 207-14.

10. Good M, Hicks MS, Grass JA, et al. Relaxation and music to reduce postsurgical pain. J Advan Nurs 2001; 33: 208-15.

11. Kubsch SM, Neveau T, Vandertie, K. Effect of cutaneous stimülation on pain reduction in emergency departmant patients. accident and emergency. Nursing 2001; 9: 143-51.

12. Kuzu N, Uçar $\mathrm{H}$. The effect of cold on the occurence of bruising, haematoma and pain at the injection site in subcutaneous low molecular weight heparin. Int J Nurs Stud 2001; 38: 51-9.

13. Brockoppa DY, Downeyb E, Powersc $P$, et al. Nurses' clinical decision-making regarding the management of pain. Int J Nurs Stud 2004; 41: 631-6.

14. Pirbudak-Çöçelli L, Bacaksız BD, Ovayolu N. Ağrı tedavisinde hemşirenin rolü. Gaziantep Tıp Dergisi 2008; 14: 53-8.

15. Yücel A. Ağrı kontrolünde hemşirenin rolü. 3. Baskı. İstanbul, Alemdar Ofset; 2007.

16. Eti-Aslan F. Ağrı Doğası ve Kontrolü. 2. Baskı. İstanbul, Avrupa Tıp Kitabevi; 2014.

17. Turan N, Öztürk A, Kaya N. "Hemsirelikte Yeni Bir Sorumluluk Alanı:Tamamlayıcı Terapi", M.Ü. Hemsirelik Bilim ve Sanat Dergisi 2010; 3: 93-8.

18. He HG, Jahja R, Lee TL, et al. Nurses' use of non-pharmacological methods in children's postoperative pain management: educational intervention study. J Advan Nurs 2010; 66: 2398-409.

19. Bicek E. Nurses' Attitudes, Knowledge, and Use of Nonpharmalogical Pain Management Techniques and Therapies. Honors Projects 2004; 1-40.

20. Ay F, Ecevit AŞ. Postoperatif ağrı ve hemşirelik uygulamaları. Ağrı 2010; 22: 21-9.
21. Özveren H. Öğrenci Hemşirelerin Ağrı Kontrolünde Kullanılan Farmakolojik Olmayan Bazı Yöntemlere İlişkin Bilgileri Sağlık Bilimleri Fakültesi Hemşirelik Dergisi 2009; 16: 59-72.

22. Akbaş $M$, Öztunç $G$. Examination of knowledge about and nursing interventions for the care of patients in pain of nurses who work at Cukurova University Medical Faculty Balcali Hospital. Pain Manag Nurs 2008; 9: 88-95.

23. Keçialan R. Lüzum halinde analjezik isteminin doktor ve hemşireler tarafından kullanımının incelenmesi. Hacettepe Üniversitesi Hemşirelik Yüksekokulu Dergisi 2001; 8.

24. Polkkı T, Vehvılaınen Vehvılaè Inen-Julkunen $\mathrm{K}$, Pıetıla ĖAM. Nonpharmacological Methods In Relieving Children's Postoperative Journal of Advanced Nursing 2001; 34: 483-492.

25. TARD. Postoperative Pain Management, Anesthesia Practice Manuals, Turkish Anesthesiology and Reanimation SocietyTARD; 2006 Available from: http://www.tard.org.tr/kilavuz/7.pdf .Accessed 2011 August 30

26. Al-Shaer D, Hill PD, Anderson MA. Nurses' knowledge and attitudes regarding pain assessment and intervention.. Medsurg Nurs. 2011; 20: 7-11.

27. Broome M, Richtsmeier A, Maikler Vet.al. Pediatric pain practices: A national survey of health professionals. Journal of Pain and Symptom Management 1996; 11: 312-20.

28. Brunier G, CarsonG, Harrison D. What do nurses know and believe about patients with pain? Results of a hospital survey. Journal of Pain and Symptom Management 1995; 10: 436-45.

29. Lynch M. Pain as the fifth vital sign. Journal of Intravenous Nursing 2001; 24: 85-93. 